\title{
Napovedniki zadovoljstva v partnerskem odnosu pri moških in ženskah"
}

\author{
Gaja Zager Kocjan ${ }^{1 *}$ in Andreja Avsec ${ }^{2}$ \\ ${ }^{1}$ Ankaran \\ ${ }^{2}$ Oddelek za psihologijo, Filozofska fakulteta, Univerza v Ljubljani
}

Povzetek: V raziskavi nas je zanimalo, ali se moški in ženske razlikujejo v tem, kaj jim je pomembno v partnerskem odnosu, in od česa je odvisno njihovo zadovoljstvo v tem odnosu. Predhodne raziskave le redko poročajo o pomembnih razlikah med spoloma v različnih napovednikih partnerskega zadovoljstva. Do podobnih ugotovitev smo prišli tudi v naši raziskavi, kjer smo med napovednike zadovoljstva vključili navezanost v odnosu, samospoštovanje in partnerjevo socialno oporo. V raziskavi je sodelovalo 200 udeležencev (od tega 63,5 \% žensk), ki so izpolnili vprašalnik Doživljanje odnosov z bližnjimi ECR-RS, Vprašalnik kakovosti odnosa QRI, Lestvico zadovoljstva s partnerskim odnosom RSS ter enopostavčno mero samospoštovanja. Pri obeh spolih je bil pomemben pozitiven napovednik zadovoljstva s partnerskim odnosom samospoštovanje, pomembni negativni napovedniki pa so bili izogibanje in anksioznost v odnosu ter konfliktnost odnosa. Med spoloma ni bilo statistično pomembnih razlik. Naši rezultati so skladni z ugotovitvami predhodnih raziskav, ki le redko poročajo o večjih razlikah med spoloma $\mathrm{v}$ različnih napovednikih.

Ključne besede: zadovoljstvo v partnerskem odnosu, razlike med spoloma, socialna opora, navezanost, samospoštovanje

\section{Predictors of relationship satisfaction for men and women}

\author{
Gaja Zager Kocjan ${ }^{1}$ and Andreja Avsec ${ }^{2}$ \\ ${ }^{1}$ Ankaran, Slovenia \\ ${ }^{2}$ Department od Psychology, Faculty of Arts, University of Ljubljana, Slovenia
}

\begin{abstract}
The present study was designed to examine the differences between genders in the perception of romantic relationship as well as in aspects of the relationship that are important for their relationship satisfaction. However, previous studies rarely report significant differences between genders in various predictors of the relationship satisfaction. In our study, similar conclusions were obtained. Relationship satisfaction was predicted with attachment, self-esteem, and partner's social support. The study included 200 participants (63.5\% of women) who completed the following questionnaires: Experience in Close Relationships - Revised Short ECR-RS, Quality of Relationship Inventory QRI, Relationship Satisfaction Scale RSS, and a single-item self-esteem measure. For both genders, significant positive predictor of their relationship satisfaction was self-esteem, while avoidance, anxiety, and conflict in the relationship were significant negative predictors. There were no significant differences between genders. These findings are consistent with the findings of previous studies, which rarely report significant gender differences in the various predictors.
\end{abstract}

Key words: relationship satisfaction, gender differences, social support, attachment, self-esteem

\#Članek je nastal v okviru doktorskega študija, ki ga je delno sofinancirala Evropska unija, in sicer iz Evropskega socialnega sklada. Sofinanciranje se izvaja v okviru Operativnega programa razvoja človeških virov za obdobje 2007-2013, 1. razvojne prioritete Spodbujanje podjetništva in prilagodljivosti; prednostne usmeritve 1.3: Štipendijske sheme.

*Naslov/Address: Gaja Zager Kocjan, Regentova ulica 3, 6280 Ankaran, e-mail: gajazkocjan@gmail.com 
Partnersko zadovoljstvo je v zadnjem desetletju postalo eno od najbolj preučevanih psiholoških konstruktov V študijah partnerskih odnosov (Fincham in Beach, 2006; Meunier in Baker, 2012). Pred tem je raziskovalce najprej zanimalo, v kolikšni meri lahko demografske spremenljivke pojasnijo razlike med posamezniki $\mathrm{v}$ partnerskem zadovoljstvu, nato so se osredotočili na preučevanje vedenja partnerjev in njegov pomen za partnersko zadovoljstvo in šele kasneje na različne procese mišljenja in čustvovanja, ki bi lahko vplivali na odnos med vedenjem in zadovoljstvom v partnerskem odnosu (Fincham in Bradbury, 1990). Redkeje pa so se raziskovalci osredotočili na možne razlike med spoloma v pomembnosti posameznih dejavnikov partnerskega zadovoljstva.

Splošno kakovost partnerskega odnosa lahko opišemo z različnimi termini, kot so na primer zakonsko ali (širše) partnersko zadovoljstvo, kakovost, prilagojenost ali sreča. Vendar pa so vsi navedeni termini nenatančno opredeljeni, zato jih je med seboj težko razlikovati, raziskovalci pa jih pogosto uporabljajo kot sinonime. Še večjo nejasnost povzroči dejstvo, da so mere teh konstruktov med seboj visoko povezane (Graham, Diebels in Barnow, 2011). Zadovoljstvo s partnerskim odnosom lahko umestimo $\mathrm{v}$ model splošnega subjektivnega blagostanja (Diener, Scollon in Lucas, 2004), ki vključuje kot pomemben vidik blagostanja poleg ocen splošnega zadovoljstva z življenjem ter pozitivnih in negativnih čustev tudi zadovoljstvo s specifičnimi področji življenja. Zadovoljstvo s partnerskim odnosom je eno od zelo pogosto ocenjenih specifičnih področij kakovosti življenja (npr. Cummins, 1996; Mallard, Lance in Michalos, 1997).

Ocena zadovoljstva s partnerskim odnosom je lahko celostna, kar pomeni, da posameznik poda oceno svojega zadovoljstva s partnerskim odnosom na splošno, zelo pogosto pa raziskovalce zanima tudi zadovoljstvo s specifičnimi vidiki partnerstva. Samoocenjevalni vprašalniki partnerskega zadovoljstva tako pogosto vključujejo ocene različnih vidikov partnerskega odnosa, vendar na podlagi seštevka ocen posameznih vidikov partnerstva omogočajo tudi splošno oceno partnerskega zadovoljstva, saj ima večina vprašalnikov enofaktorsko strukturo. Primer takih vprašalnikov so Locke-Wallaceov test prilagojenosti v zakonski zvezi (LWMAT; Locke in Wallace, 1959), Lestvica ocene partnerskega odnosa (RAS; Hendrick, 1988), Vprašalnik prepričanj o zakonski zvezi (MOQ; Huston in Vangelisti, 1991), Indeks partnerskega zadovoljstva (Funk in Rogge, 2007) ter Vprašalnik ocene odnosa (RRF; Davis in Todd, 1982). Po drugi strani nekaj vprašalnikov kakovosti partnerskega odnosa oz. prilagojenosti kaže večfaktorsko strukturo, kot npr. Indeks kakovosti zakonske zveze (QMI; Norton, 1983) ter Lestvica diadne prilagojenosti (DAS; Spanier, 1976) oz. Revidirana lestvica diadne prilagojenosti (Busby, Christensen, Crane in Larson, 1995). Pogosto pa se raziskovalci za oceno partnerskega zadovoljstva odločijo kar za uporabo ene same postavke, ki udeležence direktno sprašuje po partnerskem zadovoljstvu (npr. Erol in Orth, 2013; Roehling in Bultman, 2002; Spanier in Lewis, 1980).
Lewis in Spanier (1979) sta na osnovi pregleda obstoječe literature zasnovala model kakovosti partnerskega odnosa, kjer sta napovednike partnerskega zadovoljstva razvrstila $\mathrm{v}$ tri skupine. Prvo skupino predstavljajo osebni in socialni viri, ki jih partnerja prineseta v svoj odnos. To so lahko na primer sposobnosti, zdravje (telesno in duševno) in osebnostne lastnosti (npr. stil navezanosti, samospoštovanje). Naslednje področje se nanaša na zadovoljstvo z življenjskim slogom (npr. razporeditev dela $\mathrm{v}$ gospodinjstvu, skupno preživljanje prostega časa). Tretje področje pa predstavljajo bonitete, ki jih prejema posameznik v odnosu s partnerjem. Sem uvrščamo pozitiven partnerjev odnos (zaznana podobnost, privlačnost, enostavnost komunikacije), čustvene nagrade (izrazi ljubezni in naklonjenosti, čustvena neodvisnost), učinkovitost medsebojne komunikacije, količino interakcije med partnerjema itd. V nadaljevanju navajamo nekaj najpomembnejših ugotovitev v zvezi z različnimi dejavniki partnerskega zadovoljstva s prvega in tretjega področja, s katerimi lahko pomembno napovedujemo zadovoljstvo v partnerskem odnosu. Za prvo področje smo se odločili zato, ker zajema razmeroma stabilne dejavnike, ki jih partnerja že prineseta $\mathrm{v}$ odnos in na katerih temelji izgradnja partnerskega odnosa. Tem dejavnikom pa smo želeli dodati interakcije med partnerjema (tretje področje) kot enega ključnih elementov njunega odnosa, ki se odraža v vsakodnevnem življenju.

Psihološki konstrukt navezanosti na partnerja predstavlja pogosto teoretično osnovo za proučevanje najrazličnejših vidikov partnerskega odnosa (npr. Feeney in Noller, 1990). Mnogo raziskav (pregled v Saavedra, Rogee in Chapman, 2010) je potrdilo, da se dimenziji izogibanja in anksioznosti v odnosu povezujeta $\mathrm{z}$ višjim psihološkim stresom, $\mathrm{z}$ nižjo socialno oporo in $\mathrm{z}$ nižjim zadovoljstvom $\mathrm{v}$ partnerskem odnosu ter $\mathrm{z}$ upadom kakovosti odnosa v času. Tako se zdi, da nenehna skrb (anksioznost) in stalno emocionalno neugodje (izogibanje) oblikujeta posameznikove izkušnje v romantičnih odnosih in jih postavljata v bolj negativno luč. Campbell, Simpson, J. Boldry in D. Kashy (2005) na primer poročajo o tem, da bolj anksiozno navezani posamezniki v odnosu s svojim partnerjem zaznavajo več konfliktov ter da njihova zaznava konfliktov $\mathrm{v}$ odnosu pomembno negativno vpliva na zaznavo zadovoljstva in bližine v odnosu.

Med dispozicijske dejavnike partnerskega zadovoljstva poleg npr. osebnostnih lastnosti in navezanosti prištevamo tudi samospoštovanje. Samospoštovanje je kot celota pozitivnihinnegativnihstališčdo sebeterobčutij, skaterimi posameznik doživlja sebe in na osnovi katerih usmerja svoje ravnanje (Rosenberg, 1965), eden najpomembnejših napovednikov tako splošnega zadovoljstva $\mathrm{z}$ življenjem (Diener, 1984) kot tudi zadovoljstva na specifičnih področjih življenja - npr. partnerskega (Murray, Rose, Bellavia, Holmes in Kusche, 2002; Sciangula in Morry, 2009; Žnidaršič, 2010). Posameznik z visokim samospoštovanjem se sprejema takšen, kot je, se ceni ter je zadovoljen sam s seboj. Na podlagi teorij, ki predvidevajo vpliv splošnih predispozicij posameznika na splošno zadovoljstvo z življenjem in prek tega tudi na zadovoljstvo 
s specifičnimi področji življenja, lahko predvidevamo, da je posameznikova zaznava lastne vrednosti vključena tudi $\mathrm{v}$ oceno kakovosti odnosov in s tem v oceno zadovoljstva s temi odnosi. Takšni posamezniki se zaznavajo kot bolj všečne in privlačne, menijo, da naredijo boljši vtis na druge in da imajo na splošno boljše medosebne odnose (Baumeister, Campbell, Krueger in Vohs, 2003). S. Hendrick, Hendrick in Alder (1988) so našli pomembno povezanost med samospoštovanjem in zadovoljstvom s partnerskim odnosom pri moških, pri ženskah pa ta povezava ni bila statistično pomembna. Na vzorcu žensk pa o pomembni povezanosti med samospoštovanjem in zadovoljstvom s partnerskim odnosom poročata Wright in Busby (1997).

Posameznikovo samospoštovanje ima pomembno vlogo pri zagotavljanju kakovosti partnerskega odnosa (DeHart, Pelham in Murray, 2004). Posamezniki z nizkim samospoštovanjem se $\mathrm{v}$ težkih trenutkih za odnos (npr. konfliktne situacije) oddaljijo od svojih partnerjev, da bi se zaščitili pred občutkom zavrnitve. Nasprotno pa so v neproblematičnih obdobjih ti posamezniki s svojimi partnerji zelo zadovoljni in iščejo njihovo bližino. $\mathrm{Na}$ drugi strani tisti z visokim samospoštovanjem vzdržujejo pozitivne ocene svojih partnerjev skozi različna obdobja $\mathrm{v}$ odnosu (težka in neproblematična). To $\mathrm{v}$ splošnem pomeni, da posamezniki $\mathrm{z}$ nizkim samospoštovanjem podcenjujejo partnerjevo ljubezen, kar pomeni, da tudi težje najdejo dokaze partnerjevega sprejemanja, kar pa se povezuje $\mathrm{z}$ nižjim partnerskim zadovoljstvom (Murray idr., 2002).

Navezanost v partnerskem odnosu in samospoštovanje spadata po modelu kakovosti partnerskega odnosa (Lewis in Spanier, 1979) v prvo skupino dejavnikov, ki se nanašajo na osebne in socialne vire, ki jih partnerja prineseta $v$ medsebojni odnos. V tretjo skupino dejavnikov pa spadajo razne »bonitete«, ki jih posameznik prejema v partnerskem odnosu. Sem med drugim uvrščamo tudi socialno oporo, ki jo nudi partner. Socialno oporo v partnerskem odnosu lahko opredelimo kot proces interakcij s partnerjem, ki lajša soočanje s stresom ter drugimi življenjskimi obremenitvami in nalogami (Reis in Collins, 2000). Mnogo študij kaže, da je partnerska opora izjemno pomembna za kakovost partnerskega odnosa ter za zadovoljstvo v njunem odnosu (npr. Bradbury, Fincham in Beach, 2000; Pasch, Bradbury in Davila, 1997). Pasch in Bradbury (1998) sta na primer ugotovila pomembno povezanost med nudenjem in prejemanjem socialne opore ter zadovoljstvom s partnerskim odnosom. Rezultati njune študije so pokazali, da je ženina opora možu (spodbuda in skrb) napovedovala zadovoljstvo v odnosu, merjeno dve leti pozneje. Zanimive so tudi ugotovitve C. Cutrona (1998), ki navaja, da opora zakonca v času stresa preprečuje čustveno izolacijo med partnerjema in nastop depresije, kar bi posledično lahko vodilo do poslabšanja kakovosti partnerskega odnosa. Poleg tega socialna opora znižuje verjetnost stopnjevanja konfliktov in spodbuja občutek povezanosti med partnerjema. Nekatere študije ugotavljajo pomembne razlike med spoloma glede pomena socialne opore za partnersko zadovoljstvo. Povezanost zaznane socialne opore s partnerskim zadovoljstvom naj bi bila višja pri ženskah (Acitelli in Antonucci, 1994; Julien in Markman, 1991), poleg tega pa naj bi medosebne veščine moža (tesno povezane $\mathrm{z}$ nudenjem socialne opore) bolje napovedovale partnersko zadovoljstvo in zadovoljstvo $\mathrm{z}$ življenjem na splošno kot enake veščine pri ženi (Acitelli, 1992; White, Speisman, Jackson, Bartis in Costos, 1986).

Vprašalniki socialne opore pogosto vključujejo še nekatere vidike partnerskega odnosa, kot je npr. stopnja, do katere je odnos vir konflikta, ali stopnja, do katere je odnos zaznan kot pozitiven, pomemben in varen (Verhofstadt, Buysse, Rosseel in Peene, 2006). Konflikti med partnerjema so med drugim lahko posledica disfunkcionalne komunikacije, ki vključuje pogostejše pojavljanje vedenj, kot so trma, kritiziranje, pritoževanje, sovražnost, obrambno vedenje, izogibanje pogovoru in neodzivnost $\mathrm{v}$ odnosu s partnerjem (Fincham in Beach, 2006). Na konflikte v odnosu se lahko moški in ženske različno odzivamo. S. Lloyd (1987) navaja, da moški običajno težijo k izogibanju konfliktom, ženske pa $\mathrm{k}$ soočenju s konflikti. Ženske želijo torej razčistiti problem, moškim pa so take konfrontacije neprijetne. Izogibanje konfliktom je eden od načinov reševanja problemov, ki vodijo $\mathrm{v}$ stres in nezadovoljstvo $\mathrm{z}$ odnosom. Nasprotno velja za razreševanje konfliktov skozi pogovor, ki je, kot rečeno, bolj značilno za ženske.

Precej manj kot vloga posameznih napovednikov partnerskega zadovoljstva so raziskovalce zanimale razlike med spoloma $\mathrm{v}$ partnerskem zadovoljstvu in dejavnikih tega zadovoljstva. Ugotovitve avtorjev glede razlik med spoloma $\mathrm{v}$ partnerskem zadovoljstvu so nekonsistentne (npr. Aron in Henkemeyer, 1995; Buunk in VanYperen, 1989; Fowers, 1991). Nekateri poročajo o višjem zadovoljstvu žensk, drugi o višjem zadovoljstvu moških, najdemo pa lahko tudi študije, ki med spoloma niso odkrile pomembnih razlik. Glede razlik med spoloma v napovednikih partnerskega zadovoljstva je raziskav še manj. Sanderson in Kurdek (1993) sta na primer v svoji raziskavi preverjala moderatorsko vlogo spola pri napovedovanju zadovoljstva s partnerskim odnosom ter zavezanosti v odnosu. Ugotovila sta, da med spoloma ni bilo pomembnih razlik v napovednikih (soodvisnost med partnerjema, individualne razlike ter strategije reševanja problemov). Tudi C. Dandurand in M.-F. Lafontaine (2013) ugotavljata, da spol nima pomembne moderatorske vloge $\mathrm{v}$ odnosu med čustveno intimnostjo ter zadovoljstvom v odnosu (glej tudi Sandreson in Cantor, 2001). Lahko bi torej rekli, da malo raziskovalnih rezultatov potrjuje laična prepričanja in mite o zelo velikih razlikah med spoloma in slabših partnerskih odnosih kot posledico teh razlik.

$\mathrm{V}$ naši raziskavi so nas zanimale razlike $\mathrm{v}$ nekaterih napovednikih zadovoljstva s partnerskim odnosom med moškimi in ženskami. Podrobneje smo torej preučili moderatorsko vlogo spola $\mathrm{v}$ odnosu med različnimi napovedniki in zadovoljstvom s partnerskim odnosom. Predhodnih raziskav na to temo je malo in večinoma ne poročajo o večjih razlikah med spoloma (npr. Dandurand in Lafontaine, 2013; Sandreson in Cantor, 2001; Sanderson in Kurdek, 1993). V raziskavo smo 
kot ključne napovednike zadovoljstva zajeli razmeroma stabilne dejavnike, ki jih partnerja že prineseta $\mathrm{v}$ odnos in na katerih temelji izgradnja partnerskega odnosa - to sta dve dimenziji navezanosti v odnosu (anksioznost in izogibanje) ter samospoštovanje. Tem dejavnikom pa smo dodali interakcije med partnerjema, in sicer partnerjevo socialno oporo (opora-globina in konflikt) kot enega ključnih elementov kakovosti odnosa, ki se razvije znotraj samega odnosa in se odraža v vsakodnevnem življenju partnerjev. Pričakujemo, da bodo k razlikam med posamezniki $\mathrm{V}$ zadovoljstvu $\mathrm{s}$ partnerskim odnosom pri obeh spolih pomembno doprinesle vse vključene spremenljivke - socialna opora, navezanost in samospoštovanje. Pri obeh spolih predpostavljamo pomembno pozitivno povezanost zadovoljstva $\mathrm{v}$ odnosu $\mathrm{s}$ samospoštovanjem, oporo in globino odnosa ter statistično pomembne negativne korelacije s konfliktom $\mathrm{v}$ odnosu in dimenzijama navezanosti - anksioznostjo in izogibanjem v odnosu. Glede na predhodne raziskave (npr. Bradbury idr., 2000; Saavedra idr., 2010; Sciangula in Morry, 2009) lahko predvidevamo, da bodo vse vključene spremenljivke pomembno napovedovale zadovoljstvo v partnerskem odnosu pri obeh spolih. Pričakujemo le razlike $\mathrm{v}$ pomembnosti socialne opore za zadovoljstvo $\mathrm{v}$ partnerskem odnosu, in sicer naj bi bil njen pomen večji za ženske kot za moške (npr. Acitelli in Antonucci, 1994; Julien in Markman, 1991).

\section{Metoda}

\section{Udeleženci}

V raziskavi je sodelovalo 200 udeležencev, ki so bili v času raziskave v partnerskem razmerju. Od tega je bilo 127 (63,5 \%) udeležencev ženskega spola, 73 (36,5\%) pa moškega. Povprečna starost udeležencev je znašala 26,3 let $(S D=9,3)$, starostni razpon pa se je gibal med 17 in 61 leti. Udeleženci so bili v partnerskem odnosu v povprečju 5,6 let, vendar pa je porazdelitev dolžine partnerskega odnosa zelo desno asimetrična, zato naj omenimo še, da njen modus znaša 2 leti, mediana pa 2,5 let. Med udeleženci je bilo 59,5 \% študentov, $28 \%$ zaposlenih, $4 \%$ dijakov in $5 \%$ brezposelnih. Udeleženci so morali odgovoriti tudi na vprašanje, s kom živijo; 44,5 \% jih živi s svojimi starši, $28 \%$ s partnerjem, 12,5\% pa z enim ali več sostanovalci. Ostali živijo sami, s partnerjem pri starših ali kako drugače.

\section{Pripomočki}

Vprašalnik Doživljanje odnosov z bližnjimi ECR-RS (Experience in Close Relationships-Revised Short; Fraley, Heffernan, Vicary in Brumbaugh, 2011) je namenjen merjenju navezanosti $\mathrm{v}$ odraslosti. Individualne razlike v partnerski navezanosti organizira znotraj prostora, ki ga opredeljujeta dimenziji anksioznost in izogibanje. Posameznik na 7-stopenjski lestvici oceni, v kolikšni meri posamezna postavka oziroma trditev zanj drži (1
- sploh ne drži; 4 - nekaj vmes; 7 - popolnoma drži). Vseh postavk je deset, 3 postavke merijo anksioznost, 7 postavk pa izogibanje (primer postavke: Kadar sem v stiski, mi pomaga, če se obrnem na partnerja.). Za rezultat izračunamo vsoto odgovorov na postavke za posamezno lestvico. Vprašalnik so za raziskovalne namene $\mathrm{v}$ slovenščino prevedli trije psihologi (Zabret, osebna komunikacija). Vzvratni prevod ni bil opravljen. Avtorji vprašalnika (Fraley idr., 2011) poročajo, da znaša alfa koeficient zanesljivosti med 0,83 in 0,87 za lestvico anksioznosti $\mathrm{v}$ odnosu ter med 0,81 in $0,92 \mathrm{za}$ lestvico izogibanja v odnosu. Na našem vzorcu je znašal alfa koeficient za lestvico anksioznosti 0,78 , za lestvico izogibanja pa 0,83 . Analiza glavnih komponent je pokazala na ustreznost dvofaktorske strukture. Dve komponenti sta skupaj pojasnili 61,3\% variance vseh postavk. Vzporedna analiza je sicer pokazala, da je zgornja meja števila komponent, ki bi jih bilo smiselno izločiti, tri.

Z Vprašalnikom kakovosti odnosa QRI (Quality of Relationship Inventory; Pierce, Sarason in Sarason, 1991) ocenjujemo, v kolikšni meri posameznik zaznava dosegljivost socialne opore $\mathrm{v}$ določenem odnosu (v naši raziskavi je bil to partnerski odnos). 25 postavk se združuje v tri lestvice, ki opredeljujejo tri vidike oziroma področja odnosa - oporo (7 postavk), konflikt (12 postavk) in globino (6 postavk). Posameznik pri vsaki postavki na 4stopenjski lestvici poda svoj odgovor (1 - niti malo/nikoli; 4 -zelo veliko/vedno; primer postavke: V kolikšni meri se lahko obrneš na to osebo, da ti svetuje, ko imaš težave?). Avtorji poročajo, da znašajo alfa koeficienti zanesljivosti med 0,83 in 0,91 . Konfirmatorna faktorska analiza na 286 parih je potrdila trifaktorsko strukturo (Verhofstadt idr., 2006). Vprašalnik so v slovenščino prevedle tri študentke psihologije (Doroteja Balažic, Saša Jakin in Karmen Kajdiž) pod mentorstvom A. Avsec. Vzvratni prevod ni bil opravljen. Na našem vzorcu je komponentna analiza pokazala na dvofaktorsko strukturo. Prva komponenta je nasičala postavke, ki se nanašajo na konflikt, druga pa postavke, ki se nanašajo na oporo in globino. Z dvema komponentama smo skupaj pojasnili 41,9 \% variance vseh postavk (zgornja meja števila komponent, ki jih je smiselno izločiti glede na vzporedno analizo, je pet). Na osnovi te ugotovitve smo izračunali le rezultat na dveh lestvicah, in sicer na lestvici konflikt ter združen rezultat na lestvicah opora in globina. Alfa koeficient zanesljivosti za lestvico konflikt je znašal 0,88 , za združeno lestvico opora-globina pa 0,82 .

Lestvico zadovoljstva s partnerskim odnosom RSS (Relationship Satisfaction Scale; Gaultiere, 1995) sestavlja 30 postavk, na katere udeleženec odgovarja $\mathrm{z}$ da ali ne. Vključuje 6 podlestvic oz. področij partnerskega odnosa: stresne točke, komunikacijo, reševanje konfliktov, intimnost, čustveno reaktivnost in meje (primer postavke: Nisem zadovoljen z razporeditvijo nalog in odgovornosti pri delu in doma.). Vprašalnik je za potrebe svojega diplomskega dela $\mathrm{v}$ slovenščino prevedla in priredila $\mathrm{K}$. Guštin (2008). V prirejeni verziji udeleženec na postavke odgovarja na 5-stopenjski lestvici (1 - nikakor ne drži/ 
Tabela 1. Aritmetične sredine in standardni odkloni vseh spremenljivk za celoten vzorec in ločeno po spolu, koeficienti asimetrije in sploščenosti ter njihove standardne napake in statistična pomembnost razlik med spoloma

\begin{tabular}{|c|c|c|c|c|c|c|c|c|c|c|c|c|c|c|c|}
\hline & \multicolumn{4}{|c|}{ skupaj } & \multicolumn{4}{|c|}{ moški } & \multicolumn{4}{|c|}{ ženske } & \multirow[b]{2}{*}{$t^{*}$} & \multirow[b]{2}{*}{$S E_{\Delta M}$} & \multirow[b]{2}{*}{$p$} \\
\hline & $M$ & $S D$ & As & $S p l$ & $M$ & $S D$ & As & $S p l$ & $M$ & $S D$ & As & Spl & & & \\
\hline $\begin{array}{l}\text { QRI - } \\
\text { opora-globina }\end{array}$ & 46,52 & 4,51 & $-1,45$ & 2,27 & 46,12 & 4,75 & $-1,18$ & 1,47 & 46,74 & 4,37 & $-1,65$ & 3,09 & $-0,93$ & 0,66 & 0,35 \\
\hline $\begin{array}{l}\text { QRI - konf- } \\
\text { liktnost }\end{array}$ & 24,95 & 6,20 & 0,39 & 0,01 & 24,47 & 6,02 & 0,17 & $-0,01$ & 25,22 & 6,31 & 0,48 & $-0,01$ & $-0,83$ & 0,91 & 0,41 \\
\hline $\begin{array}{l}\text { ECR - ank- } \\
\text { sioznost }\end{array}$ & 5,41 & 2,67 & 1,03 & 0,21 & 5,04 & 2,41 & 1,13 & 0,63 & 5,62 & 2,80 & 0,95 & $-0,02$ & $-1,49$ & 0,39 & 0,14 \\
\hline $\begin{array}{l}\text { ECR - izo- } \\
\text { gibanje }\end{array}$ & 19,56 & 4,78 & 1,10 & 0,49 & 20,03 & 4,12 & 0,69 & $-0,15$ & 19,29 & 5,12 & 1,28 & 0,73 & 1,05 & 0,71 & 0,30 \\
\hline $\begin{array}{l}\text { SISE } \\
\text { (samospošt.) }\end{array}$ & 5,19 & 1,39 & $-0,80$ & 0,35 & 5,38 & 1,51 & $-1,11$ & 0,94 & 5,08 & 1,31 & $-0,64$ & 0,13 & 1,50 & 0,20 & 0,14 \\
\hline $\begin{array}{l}\text { RSS } \\
\text { (zadovoljstvo) }\end{array}$ & 87,47 & 16,27 & $-0,62$ & 0,32 & 86,86 & 15,66 & $-0,30$ & 0,20 & 87,82 & 16,66 & $-0,78$ & 0,63 & $-0,40$ & 2,40 & 0,70 \\
\hline
\end{tabular}

nikoli, 5 - popolnoma drži/vedno). K. Guštin (2008) poroča, da se na slovenskem vzorcu alfa koeficienti lestvic gibajo v razponu med 0,38 in 0,71 . Zanesljivost celotnega vprašalnika pa je 0,84 . Njeno verzijo vprašalnika smo uporabili tudi v naši raziskavi. Uporabili smo le skupen seštevek. Komponentna analiza je sicer pokazala na možno eno- ali štirikomponentno rešitev, vendar pa se je pri slednji pojasnjena varianca nesistematično porazdelila med komponente (glede na vzporedno analizo bi lahko izločili največ pet komponent). S prvo komponento smo pojasnili $26,6 \%$ variance v vseh postavkah. Alfa koeficient zanesljivosti za skupen rezultat je znašal 0,89.

$\mathrm{V}$ raziskavo smo vključili tudi Enopostavčno mero samospoštovanja SISE (Single-Item Self-Esteem Scale; Robins, Hendin in Trzesniewski, 2001). Mero sestavlja ena sama postavka: »Imam visoko samospoštovanje.« V prvotni verziji je bila ocenjevalna lestvica 5-stopenjska, v naši raziskavi pa smo zaradi večje informativnosti uporabili 7-stopenjsko lestvico (1 - sploh ne drži; 7 - popolnoma drži). Avtorji poročajo o zadovoljivi zanesljivosti in visoki veljavnosti te mere. Korelacije $\mathrm{z}$ Rosenbergovim vprašalnikom samospoštovanja RSE (Rosenberg Self-Esteem Scale; Rosenberg, 1965), ki velja za enega najpogosteje uporabljanih, so se gibale $\mathrm{v}$ razponu med 0,72 in 0,76 , po popravku za atenuacijo pa med 0,89 in 0,94 . Avtorji so zanesljivost SISE ocenili po Heiseovem postopku, ki temelji na vzorcu avtokorelacij v treh časovnih točkah in nudi oceno retestne zanesljivosti. Dobljeni koeficient zanesljivosti je znašal 0,75 (Robins idr., 2001).

\section{Postopek}

Vzorčenje je potekalo po principu snežne kepe. Vprašalnik, ki je bil $\mathrm{v}$ elektronski obliki dostopen na spletu, smo po elektronski pošti posredovali prijateljem in znancem ter jih prosili, naj ga - če so trenutno $\mathrm{v}$ partnerskem razmerju - izpolnijo in tudi sami posredujejo naprej. Povezavo, na kateri je bil vprašalnik dostopen, smo objavili tudi na spletnih straneh (npr. www.psiha. net), forumih in spletnih skupnostih (npr. Facebook). Izpolnjevanje vprašalnikov je trajalo 10 do 15 minut. Udeleženci so morali podati odgovore na vsa vprašanja, sicer nadaljnje izpolnjevanje vprašalnika ni bilo mogoče. Manjkajočih podatkov torej ni bilo.

\section{Rezultati}

V tabeli 1 povzemamo osnovne opisne statistike za vse spremenljivke, vključene $\mathrm{v}$ raziskavo. Aritmetične sredine in standardni odkloni so prikazani za celoten vzorec ter ločeno za moške in ženske. Od normalne porazdelitve najbolj odstopa porazdelitev rezultatov na lestvici QRI opora-globina, ki je pri obeh spolih levo asimetrična in koničasta. Odstopanje od normalnosti pri odvisni spremenljivki, zadovoljstvu v partnerskem odnosu (RSS), je zmerno, zato smo se odločili za uporabo parametričnih testov. Tabela prikazuje tudi statistično pomembnost razlik med spoloma ( $t$-test). Vidimo lahko, da med spoloma pri nobeni izmed spremenljivk ni statistično pomembnih razlik.

Pri obeh spolih je večina korelacij med spremenljivkami, zajetimi $\mathrm{v}$ raziskavo, statistično pomembna na 1-odstotni ravni tveganja (tabela 2). Pri ženskah so izjema korelacije samospoštovanja $\mathrm{z}$ lestvicama vprašalnika socialne opore ter $z$ izogibanjem. Pri moških pa sta statistično nepomembni korelaciji med oporo-globino in konfliktnostjo ter samospoštovanjem. Spremenljivke anksioznost, izogibanje in konfliktnost $\mathrm{z}$ ostalimi napovedniki kakovosti partnerskega odnosa ter s samospoštovanjem korelirajo negativno, med seboj pa pozitivno. Tako pri moških kot pri ženskah sta najvišji negativni korelaciji med konfliktnostjo in zadovoljstvom s partnerskim odnosom, tej pa sledi negativna korelacija med oporo-globino in izogibanjem.

Preverili smo tudi statistično pomembnost razlik med spoloma v korelacijah med preučevanimi spremenljivkami. 
Tabela 2. Korelacije (Pearsonovi korelacijski koeficienti) med spremenljivkami in njihova statistična pomembnost ločeno za moške (pod diagonalo) in ženske (nad diagonalo)

\begin{tabular}{lcccccc}
\hline & 1 & 2 & 3 & 4 & 5 & 6 \\
\hline 1. QRI - opora-globina & $/$ & $-0,49^{* *}$ & $-0,34^{* *}$ & $-0,72^{* *}$ & 0,03 & $0,53^{* *}$ \\
2. QRI - konfliktnost & $-0,14$ & $/$ & $0,45^{* *}$ & $0,51^{* *}$ & $-0,13$ & $-0,76^{* *}$ \\
3. ECR - anksioznost & $-0,39^{* *}$ & $0,28^{*}$ & $/$ & $0,42^{* *}$ & $-0,34^{* *}$ & $-0,50^{* *}$ \\
4. ECR - izogibanje & $-0,72^{* *}$ & $0,42^{* *}$ & $0,44^{* *}$ & $/$ & $-0,13$ & $-0,65^{* *}$ \\
5. SISE (samospoštovanje) & 0,20 & $-0,30^{* *}$ & $-0,29^{*}$ & $-0,35^{* *}$ & $/$ & $0,29^{* *}$ \\
6. RSS (zadovoljstvo) & $0,31^{* *}$ & $-0,75^{* *}$ & $-0,50^{* *}$ & $-0,53^{* *}$ & $0,45^{* *}$ & $/$ \\
\hline
\end{tabular}

Opombe. ${ }^{*} p<0,05 ;{ }^{* *} p<0,01$.

Pri ženskah se je kot pomembno višja izkazala negativna korelacija med oporo-globino in konfliktnostjo $\mathrm{v}$ odnosu $(Z=-2,64 ; p<0,01)$. V višini ostalih korelacij se moški in ženske med seboj niso statistično pomembno razlikovali.

Nadalje nas je zanimalo, kolikšen delež variance $\mathrm{v}$ zadovoljstvu s partnerskim odnosom lahko pojasnimo s samospoštovanjem, navezanostjo in socialno oporo pri posameznem spolu. Podatki so ustrezali predpostavkam linearne regresijske analize (linearni odnosi, homoscedastičnost in približno normalna porazdelitev rezidualov). Regresijsko analizo smo izvedli v treh korakih (za vključevanje napovednikov smo uporabili metodo Enter), najprej na vzorcu moških udeležencev.
$\mathrm{V}$ prvem koraku smo $\mathrm{v}$ model vključili starost in dolžino partnerskega odnosa. Tako smo nadzirali vpliv demografskih spremenljivk. Pri moških s tema dvema napovednikoma nismo pojasnili (skoraj) nič variance v zadovoljstvu s partnerskim odnosom. V naslednjem koraku smo $\mathrm{v}$ model vključili stabilne osebnostne lastnosti, in sicer dimenziji navezanosti (ECR) ter mero samospoštovanja. $Z$ njimi smo pojasnili $45 \%$ variance v zadovoljstvu s partnerskim odnosom. Kot statistično pomembni napovedniki so se izkazali vsi trije - izogibanje in anksioznost $\mathrm{v}$ odnosu (ECR) ter samospoštovanje. $\mathrm{V}$ tretjem koraku smo $v$ model vključili še interakcije med partnerjema oziroma področja socialne opore (QRI) ter

Tabela 3. Rezultati hierarhične regresijske analize pri pojasnjevanju variance v zadovoljstvu s partnerskim odnosom

\begin{tabular}{|c|c|c|c|c|c|c|c|c|}
\hline & \multicolumn{4}{|c|}{ moški } & \multicolumn{4}{|c|}{ ženske } \\
\hline & $\Delta R^{2}$ & $B$ & $95 \%$ IZ za $B$ & $\beta$ & $\Delta R^{2}$ & $B$ & $95 \%$ IZ za $B$ & $\beta$ \\
\hline 1. korak & 0,00 & & & & $0,09^{* *}$ & & & \\
\hline Starost & & 0,09 & {$[-0,38 ; 0,55]$} & 0,05 & & $-0,43$ & {$[-1,16 ; 0,03]$} & $-0,26$ \\
\hline Trajanje odnosa & & $-0,04$ & {$[-0,23 ; 0,15]$} & $-0,05$ & & $-0,09$ & {$[-0,94 ; 0,76]$} & $-0,05$ \\
\hline 2. korak & $0,45^{* * *}$ & & & & $0,45^{* * *}$ & & & \\
\hline Starost & & 0,33 & {$[-0,03 ; 0,68]$} & 0,17 & & 0,05 & {$[-0,50 ; 0,59]$} & 0,03 \\
\hline Trajanje odnosa & & $-0,05$ & {$[-0,20 ; 0,09]$} & $-0,07$ & & $-0,40$ & {$[-1,02 ; 0,22]$} & $-0,21$ \\
\hline ECR-R - anksioznost & & $-1,97$ & {$[-3,30 ;-0,63]$} & $-0,30^{* *}$ & & $-1,51$ & {$[-2,37 ;-0,65]$} & $-0,26^{* *}$ \\
\hline ECR-R - izogibanje & & $-1,25$ & {$[-2,05 ;-0,44]$} & $-0,33^{* *}$ & & $-1,57$ & {$[-2,05 ;-1,10]$} & $-0,48^{* * *}$ \\
\hline SISE (samospošt.) & & 2,83 & {$[0,77 ; 4,88]$} & $0,27^{* *}$ & & 1,85 & {$[0,17 ; 3,52]$} & $0,15^{*}$ \\
\hline 3. korak & $0,28^{* * *}$ & & & & $0,20^{* * *}$ & & & \\
\hline Starost & & 0,41 & {$[0,16 ; 0,67]$} & $0,22^{* *}$ & & 0,21 & {$[-0,22 ; 0,63]$} & 0,12 \\
\hline Trajanje odnosa & & $-0,08$ & {$[-0,19 ; 0,03]$} & $-0,10$ & & $-0,52$ & {$[-1,01 ; 0,04]$} & $-0,27^{*}$ \\
\hline ECR-R - anksioznost & & $-1,54$ & {$[-2,50 ;-0,58]$} & $-0,24^{* *}$ & & $-0,53$ & {$[-1,23 ; 0,16]$} & $-0,09$ \\
\hline ECR-R - izogibanje & & $-0,42$ & {$[-1,24 ; 0,39]$} & $-0,11$ & & $-0,92$ & {$[-1,40 ;-0,43]$} & $-0,28^{* * *}$ \\
\hline SISE (samospošt.) & & 1,92 & {$[0,45 ; 3,39]$} & $0,18^{*}$ & & 2,06 & {$[0,76 ; 3,35]$} & $0,16^{* *}$ \\
\hline QRI - opora-globina & & 0,13 & {$[-0,54 ; 0,80]$} & 0,04 & & 0,05 & {$[-0,50 ; 0,60]$} & 0,01 \\
\hline QRI - konfliktnost & & $-1,58$ & {$[-1,97 ;-1,19]$} & $-0,61^{* * *}$ & & $-1,41$ & {$[-1,73 ;-1,10]$} & $-0,54^{* * *}$ \\
\hline Skupaj & 0,74 & & & & 0,73 & & & \\
\hline
\end{tabular}

Opombe. ${ }^{*} p<0,05 ;{ }^{* *} p<0,01 ;{ }^{* * *} p<0,001$. 
z njimi dodatno pojasnili $28 \%$ variance. Zadovoljstvo je pomembno napovedovala le konfliktnost v odnosu (QRI). Skupaj smo pojasnili $74 \%$ variance v odvisni spremenljivki (populacijski $R^{2}=0,71 ; F=25,78 ; p<0,001$ ).

Tudi pri ženskah se starost in trajanje odnosa nista izkazala kot pomembna napovednika zadovoljstva $\mathrm{v}$ partnerskem odnosu. V drugem koraku sta tako kot pri moških zadovoljstvo pomembno napovedovali obe dimenzijinavezanostivodnosu(ECR)tersamospoštovanje. $\mathrm{S}$ temi napovedniki smo pojasnili dodatnih $45 \%$ variance. $\mathrm{V}$ tretjem koraku je med dimenzijama socialne opore zadovoljstvo pomembno napovedovala le konfliktnost. $\mathrm{V}$ tem koraku smo pojasnili $20 \%$ variance $\mathrm{Z}$ modelom vseh spremenljivk skupaj smo pojasnili $73 \%$ variance v odvisni spremenljivki (populacijski $R^{2}=0,71 ; F=44,69$; $p<0,001)$.

\section{Razprava}

Rezultati naše raziskave kažejo, da starost in trajanje partnerskega odnosa ne napovedujeta pomembno zadovoljstva $\mathrm{v}$ odnosu. Kot pomembni napovedniki so se pri obeh spolih izkazali obe dimenziji navezanosti $\mathrm{v}$ odnosu, samospoštovanje ter konfliktnost odnosa. Razlik med spoloma v napovednikih zadovoljstva nismo našli.

Najprej smo v raziskavi preverili, ali se moški in ženske med seboj razlikujejo v merjenih spremenljivkah, in ugotovili, da med njimi ni pomembnih razlik. Tudi sicer metaanalize kažejo, da so razlike med spoloma večinoma majhne (Hyde, 2005). Treba pa je omeniti, da so pri nekaterih konstruktih sicer majhne razlike med spoloma zelo konsistentne. Raziskavena primer konsistentno kažejo nekoliko višje samospoštovanje (Orth, Trzesniewski in Robins, 2010) ter nižjo anksioznost in višje izogibanje v odnosu (Del Giudice, 2011) pri moških. Rezultati naše raziskave torej niso skladni s temi ugotovitvami, saj ni prišlo do pomembnih razlik med spoloma, vendar pa tudi Del Giudice (2011) ugotavlja, da na vzorcih, zbranih preko spleta, razlike med spoloma v navezanosti niso bile pomembne.

Nadalje so nas zanimale povezave med izbranimi dejavniki partnerskega zadovoljstva in partnerskim zadovoljstvom posebej za vsak spol. Ker Fischerjeve Z-transformacije kažejo, da korelacije večinoma niso pomembno različne med spoloma, jih bomo na tem mestu interpretirali za celoten vzorec. Po pričakovanju je partnersko zadovoljstvo pomembno povezano z vsemi izbranimi spremenljivkami. Pomembne povezave z obema vidikoma socialne opore-oporo-globino terkonfliktnostjo - so skladne s predhodnimi raziskavami (npr. Bradbury idr., 2000; Pasch idr., 1997; Pasch in Bradbury, 1998). Enako velja tudi za povezavo s samospoštovanjem, ki potrjuje domnevo, da je posameznikovo zaznavanje lastne vrednosti pomemben del kakovosti njegovih odnosov oziroma zadovoljstva s temi odnosi. Podobne so tudi ugotovitve nekaterih predhodnih raziskav (Murray idr., 2002; Sciangula in Morry, 2009; Žnidaršič, 2010). Od obeh dimenzij navezanosti je (posebej pri moških) izogibanje precej močneje kot anksioznost v odnosu, povezano s partnerskim nezadovoljstvom, kar je tudi skladno s predhodnimi raziskavami (Saavedra idr., 2010). Izogibanje v odnosu namreč onemogoči zadovoljevanje temeljne potrebe po pripadnosti (Baumeister in Leary, 1995; Deci in Ryan, 2000) in lahko vodi k čustveni osamljenosti (Weiss, 1973).

Tudi rezultati regresijske analize so pokazali, da med spoloma ni večjih razlik $\mathrm{v}$ pomembnosti posameznih napovednikov za zadovoljstvo $\mathrm{v}$ partnerskem odnosu. $\mathrm{V}$ prvi stopnji regresijske analize smo kot napovednika partnerskega zadovoljstva vključili starost udeležencev in trajanje razmerja. Napovednika se pri nobenem od spolov nista izkazala kot statistično pomembna. Pretekle raziskave so sicer pokazale na pomemben vpliv stadija, $\mathrm{v}$ katerem je družina, na partnersko zadovoljstvo. Partnersko zadovoljstvo običajno upade z rojstvom prvega otroka, je najnižje, ko so otroci v adolescenci, in se zviša ob odhodu otrok od doma (Doherty in Jacobson, 1982; White in Edwards, 1990). V naši raziskavi teh povezav nismo zaznali, kar je verjetno povezano tudi $\mathrm{z}$ demografsko strukturo vzorca, ki so ga sestavljali pretežno študenti, živeči s svojimi starši.

V drugem koraku smo v regresijsko analizo vključili navezanost in samospoštovanje, ki ju lahko označimo kot dispozicijski lastnosti in sta ju Lewis in Spanier (1979) uvrstila v skupino lastnosti, ki jih posameznik prinese $\mathrm{v}$ partnersko zvezo. Kot pomembna negativna napovednika sta se pri obeh spolih izkazala izogibanje in anksioznost $\mathrm{v}$ odnosu kot del konstrukta navezanosti, pomemben pozitiven napovednik pri obeh spolih pa je bilo samospoštovanje. Kot ugotavljajo tudi predhodne raziskave (npr. Saavedra idr., 2010), je s partnerskim zadovoljstvom še posebej močno povezano izogibanje $\mathrm{v}$ odnosu, torej občutja nelagodja ob intimnosti in bližini. $\mathrm{Na}$ osnovi večjega izogibanja intimnosti $\mathrm{v}$ odnosu lahko torej tako pri moških kot pri ženskah napovemo pomembno nižje zadovoljstvo $\mathrm{z}$ njihovim partnerskim odnosom, saj v tem primeru ne uspejo zadovoljiti svoje potrebe po intimnosti oz. pripadnosti (Baumeister in Leary, 1995; Deci in Ryan, 2000). Raziskave (pregled v Saavedra idr., 2010) so pokazale, da se tudi dimenzija anksioznosti $\mathrm{v}$ odnosu povezuje $\mathrm{z}$ nižjim zadovoljstvom $\mathrm{v}$ partnerskem odnosu ter $\mathrm{z}$ upadom kakovosti odnosa $\mathrm{v}$ času. Campbell in sodelavci (2005) ugotavljajo, da bolj anksiozno navezani posamezniki odnos zaznavajo kot bolj konflikten, kar nadalje pomembno negativno vpliva na zaznavo zadovoljstva in bližine v odnosu. Tudi v našem primeru se je anksioznost pri obeh spolih izkazala kot pomemben negativni napovednik zadovoljstva $\mathrm{v}$ odnosu, čeprav nekoliko šibkejši $\mathrm{v}$ primerjavi $\mathrm{z}$ izogibanjem. Predhodne raziskave potrjujejo tudi pomembno vlogo samospoštovanja pri napovedovanju zadovoljstva $\mathrm{s}$ partnerskim odnosom (npr. Murray idr., 2002; Sciangula in Morry, 2009; Žnidaršič, 2010). Tudi naša raziskava je pokazala, da lahko na osnovi posameznikove ocene lastne vrednosti pri moških in pri ženskah napovedujemo njihovo zadovoljstvo s partnerskim odnosom. Posamezniki $\mathrm{z}$ višjim samospoštovanjem med drugim menijo, da znajo na druge narediti boljši vtis in da imajo na splošno z drugimi boljše odnose kakor tisti $\mathrm{z}$ nižjim samospoštovanjem (Baumeister idr., 2003). Pri samospoštovanju je še 
posebej težko teoretično predvideti, empirično pa z našo korelacijsko študijo tudi ne moremo določiti, ali je višje samospoštovanje vzrok za boljše partnersko zadovoljstvo (top-down model) ali boljša izkušnja s partnerskim odnosom in s tem višje partnersko zadovoljstvo vpliva tudi na višje zadovoljstvo s seboj (bottom-up model).

$\mathrm{V}$ zadnjem, tretjem koraku smo kot napovednika zadovoljstva s partnerskim odnosom v regresijsko analizo vključili še dva vidika socialne opore v odnosu. Socialno oporo uvrščamo v tretjo skupino dejavnikov zadovoljstva s partnerskim odnosom po Lewisu in Spanierju (1979) - to so »bonitete«, ki jih posameznik prejema v svojem odnosu s partnerjem. Tako pri moških kot pri ženskah se je kot pomemben napovednik izkazala le konfliktnost v odnosu. Po S. Lloyd, Cateju in J. Henton (1984) se moški navadno izogibajo konfrontacijam, ženske pa si želijo soočenja s konflikti ter njihovega razreševanja skozi pogovor, kar naj bi bil bolj konstruktiven pristop. Glede na naše rezultate lahko kljub značilni razliki med spoloma v soočanju s konflikti zaključimo, da se konfliktnost odnosa pri moških in ženskah v enaki meri povezuje z zadovoljstvom v odnosu. Čemu je tako in ali bolj konstruktivni načini soočanja s konflikti, značilni za ženske, res ne ublažijo negativnega učinka konfliktnosti na zadovoljstvo $\mathrm{v}$ partnerskem odnosu, na osnovi naše raziskave ne moremo zaključiti. Več predhodnih raziskav je pokazalo tudi na pomen partnerske opore za zadovoljstvo v partnerskem odnosu (Bradbury idr., 2000; Pasch in Bradbury, 1998; Pasch idr., 1997). Partnerjeva opora naj bi preprečevala emocionalno izolacijo med partnerjema, zniževala verjetnost stopnjevanja konfliktov ter spodbujala občutek povezanosti (Pasch in Bradbury, 1998). Nekatere predhodne študije so sicer ugotovile pomembne razlike med spoloma. Povezanost zaznane socialne opore s partnerskim zadovoljstvom naj bi bila višja pri ženskah (Julien in Markman, 1991; Acitelli in Antonucci, 1994), vendar pa v naši raziskavi lestvica opore-globine ni pomembno napovedovala zadovoljstva $\mathrm{v}$ partnerskem odnosu pri nobenem od spolov.

\section{Zaključki}

Predhodne raziskave redko poročajo o večjih razlikah med spoloma $\mathrm{v}$ različnih napovednikih zadovoljstva $\mathrm{v}$ partnerskem odnosu. Podobne so tudi ugotovitve naše raziskave, kjer smo med ključne napovednike zadovoljstva zajeli dve dimenziji navezanosti v odnosu (anksioznost in izogibanje), samospoštovanje (področje osebnih in socialnih virov, ki jih partnerja prineseta v svoj odnos) in partnerjevo socialno oporo - oporo-globino ter konfliktnost (bonitete, kijih prejema posameznik v odnosu s partnerjem). Pri obeh spolih so bili napovedniki podobno pomembni za zadovoljstvo s partnerskim odnosom. To so bili samospoštovanje, izogibanje in anksioznost v odnosu ter konfliktnost odnosa. Med spoloma ni bilo pomembnih razlik.

Omeniti je potrebno še omejitve raziskave. Posebej bi izpostavili nekatere značilnosti vzorca, na primer nekoliko manjši numerus, nesorazmeren delež moških in žensk ter desno asimetrično porazdelitev starosti udeležencev. Prihodnje raziskave bi se morale torej osredotočiti na bolj heterogeno skupino udeležencev. Druga pomanjkljivost je zbiranje podatkov prek spleta. Demografska slika vzorcev iz spletnih raziskav je bolj omejena (Gosling, Vazier, Srivastava in John, 2004), kar bi lahko povezovali tudi z manjšim številom starejših udeležencev, ki jih takšne spletne raziskave težje dosežejo. Poleg tega so spletne raziskave zaradi močne samoselekcije potencialnih udeležencev tudi precej pristranske glede na strukturo po spolu (več udeležencev je ženskega spola). Tako neravnovesje v strukturi vzorca glede na spol poraja vprašanje o reprezentativnosti vzorca moških udeležencev, ki sodelujejo $\mathrm{v}$ spletnih raziskavah (več o tem v Krantz in Dalal, 2000).

Pomembna pomanjkljivost je tudi, da med napovednike zadovoljstva nismo zajeli vseh relevantnih področij - izpustili smo na primer vidike zadovoljstva $\mathrm{s}$ skupnim življenjskim slogom (druga skupina dejavnikov zadovoljstva $\mathrm{s}$ partnerskim odnosom po Lewisu in Spanierju, 1979). Vprašalniki iz tega področja so zelo obsežni in zato niso bili primerni za aplikacijo v naši spletni raziskavi poleg že uporabljenih vprašalnikov, saj bi se čas izpolnjevanja precej podaljšal. V prihodnjih raziskavah bi bilo smiselno med napovednike partnerskega zadovoljstva zajeti tudi bolj temeljne dimenzije osebnosti (ki jih lahko uvrstimo $\mathrm{v}$ prvo skupino dejavnikov partnerskega zadovoljstva po Lewisu in Spanierju, 1979) in preveriti, kakšna je $\mathrm{v}$ tem primeru prirastna napovedna veljavnost ostalih napovednikov. Predvidevamo, da se zaradi precejšnjega prekrivanja s temeljnimi osebnostnimi dimenzijami njihova napovedna veljavnost $\mathrm{v}$ tem primeru zmanjša. Poleg tega bi bilo zanimivo preučiti tudi, kako se vloga posameznih dejavnikov zadovoljstva spreminja s starostjo oziroma trajanjem partnerskega odnosa.

\section{Literatura}

Acitelli, L. K. (1992). Gender differences in relationship awareness and marital satisfaction among young married couples. Personality and Social Psychology Bulletin, 18, 102-110.

Acitelli, L. K. in Antonucci, T. C. (1994). Gender differences in the link between marital support and satisfaction in older couples. Journal of Personality and Social Psychology, 67, 688-698.

Aron, A. in Henkemeyer, L. (1995). Marital satisfaction and passionate love. Journal of Social and Personal Relationships, 12, 139-146.

Baumeister, R. F. in Leary, M. R. (1995). The need to belong: Desire for interpersonal attachments as a fundamental human motivation. Psychological Bulletin, 117, 497-529.

Baumeister, R. F., Campbell, J. D., Krueger, J. I. in Vohs, K. D. (2003). Does high self-esteem cause better performance, interpersonal success, happiness, or healthier life-styles? Psychological Science in the Public Interest, 4, 1-44.

Bradbury, T. N., Fincham, F. D. in Beach, S. R. H. (2000). Research on the nature and determinants of marital satisfaction. Journal of Marriage and the Family, 62, 964-980. 
Busby, D. M., Christensen, C., Crane, D. R. in Larson, J. H. (1995). A revision of the Dyadic Adjustment Scale for use with distressed and nondistressed couples: Construct hierarchy and multidimensional scales. Journal of Marital and Family Therapy, 21, 289-308.

Buunk, B. P. in VanYperen, N. W. (1989). Social comparison, equality and relationship satisfaction: Gender differences over a ten-year period. Social Justice Research, 3, 157-180.

Campbell, L., Simpson, J. A., Boldry, J. in Kashy, D. A. (2005). Perceptions of conflict and support in romantic relationships: The role of attachment anxiety. Journal of Personality and Social Psychology, 88, 510-531.

Cummins, R. A. (1996). The domains of life satisfaction: An attempt to order chaos. Social Indicators Research, 38, 303-328.

Cutrona, C. E. (1998). Social support as determinants of marital quality: The interplay of negative and supportive behaviors. V G. R. Pierce, B. R. Sarrason in I. G. Sarrason (ur.), Handbook of social support and the family (str. 173-194). New York: Plenum Press.

Dandurand, C. in Lafontaine, M.-F. (2013). Intimacy and couple satisfaction: The moderating role of romantic attachment. The International Journal of Psychological Studies, 5, 74-90.

Davis, K. E. in Todd, M. J. (1982). Friendship and love relationships. V K. E. Davis in T. O. Mitchell (ur.), Advances in descriptive psychology: Vol. 2. (str. 79112). Greenwich, CT, ZDA: JAI Press.

Deci, E. L. in Ryan, R. M. (2000). The "what" and "why" of goal pursuits: Human needs and the selfdetermination of behavior. Psychological Inquiry, 11, 227-268.

DeHart, T., Pelham, B. in Murray, S. (2004). Implicit dependency regulation: Self-esteem, relationship closeness, and implicit evaluations of close others. Social Cognition, 22, 126-146.

Del Giudice, M. (2011). Sex differences in romantic attachment: A meta-analysis. Personality and Social Psychology Bulletin, 37, 193-214.

Diener, E. (1984). Subjective well-being. Psychological Bulletin, 95, 542-575.

Diener, E., Scollon, C. N. in Lucas, R. E. (2004). The evolving concept of subjective well-being: The multifaceted nature of happiness. V P.T. Costa in I.C. Siegler (ur.), Advances in cell aging and gerontology: Vol. 15. (str. 187-220). Amsterdam: Elsevier.

Doherty, W. J. in Jacobson, N. S. (1982). Marriage and the family. V B. B. Wolman (ur.), Handbook of developmental psychology (str. 667-679). Englewood Cliffs, NJ, ZDA: Prentice-Hall.

Erol, R. in Orth, U. (2013). Actor and partner effects of self-esteem on relationship satisfaction and the mediating role of secure attachment between the partners. Journal Of Research In Personality, 47, 26-35.

Feeney, J. A. in Noller, P. (1990). Attachment styles as a predictor of adult romantic relationships. Journal of Personality and Social Psychology, 58, 281-291.
Fincham, F. D. in Beach, S. R. H. (2006). Relationship satisfaction. V A. L. Vangelisti in D. Perlman (ur.), The Cambridge Handbook of Personal Relationships (str. 579-594). Cambridge, VB: Cambridge University Press.

Fincham, F. D. in Bradbury, T. N. (1990). The psychology of marriage: Basic issues and applications. New York, NY, ZDA: Guilford Press.

Fowers, B. J. (1991). His and her marriage: A multivariate study of gender and marital satisfaction. Sex Roles, 24, 209-221.

Fraley, R. C., Heffernan, M. E., Vicary, A. M. in Brumbaugh, C. C. (2011). The Experiences in Close Relationships-Relationship Structures Questionnaire: A method for assessing attachment orientations across relationships. Psychological Assessment, 23, $615-625$.

Funk, J. L. in Rogge, R. D. (2007). Testing the ruler with item response theory: Increasing precision of measurement for relationship satisfaction with the Couples Satisfaction Index. Journal of Family Psychology, 21, 572-583.

Gaultiere, B. (1995). Relationship Satisfaction Survey. Sneto 10. maja $2010 \mathrm{~s}$ http:// www.newhopenow.org/ selfhelp/relationship.html

Gosling, S. D., Vazier, S., Srivastava, S. in John, O. P. (2004). Should we trust web-based studies? A comparative analysis of six preconceptions about internet questionnaires. American Psychologist, 59, 93-104.

Graham, J. M., Diebels, K. J. in Barnow, Z. B. (2011). The reliability of relationship satisfaction: A reliability generalization meta-analysis. Journal of Family Psychology, 25, 39-48.

Guštin, K. (2008). Pričakovanja partnerjev o starševski vlogi $v$ času nosečnosti $v$ povezavi s partnerski odnosom (neobjavljeno diplomsko delo). Filozofska fakulteta Univerze v Ljubljani, Ljubljana, Slovenija.

Hendrick, C., Hendrick, S. S. in Alder, N. L. (1988). Romantic relationships: Love, satisfaction, and staying together. Journal of Personality and Social Psychology, 54, 980-988.

Hendrick, S. S. (1988). A generic measure of relationship satisfaction. Journal of Marriage and the Family, 50, 93-98.

Huston, T. L. in Vangelisti, A. L. (1991). Socioemotional behavior and satisfaction in marital relationships: A longitudinal study. Journal of Personality and Social Psychology, 61, 721-733.

Hyde, J. S. (2005). The Gender Similarities Hypothesis. American Psychologist, 60, 581-592.

Julien, D. in Markman, H. J. (1991). Social support and social networks as determinants of individual and marital outcomes. Journal of Social and Personal Relationships, 8, 549-568.

Krantz, J. H. in Dalal, R. (2000). Validity of web-based psychological research. V M. H. Birnbaum (ur.), Psychological experiments on the Internet (str. 3560). San Diego, CA, ZDA: Academic Press. 
Lewis, R. in Spanier, G. (1979). Theorizing about the quality and stability of marriage. V W. R. Burr, R. Hill, F. I. Nye in I. Reiss (ur.), Contemporary Theories about the Family: Vol. 2. (str. 268-294). New York: Free Press.

Lloyd, S. A. (1987). Conflict in premarital relationships: Differential perception of males and females. Family Relations, 38, 290-294.

Lloyd, S. A., Cate, R. M. in Henton, J. (1984). Predicting premarital relationship stability: A methodological refinement. Journal of Marriage and the Family, 46, $71-76$

Locke, H. J. in Wallace, M. (1959). Short marital adjustment and prediction test: Reliability and validity. Marriage and Family Living, 21, 251-255.

Mallard, A. G. C., Lance, C. in Michalos, A. C. (1997). Culture as a moderator of overall life satisfactionlife facet satisfaction relationships. Social Indicators Research, 40, 259-284.

Meunier, V. in Baker, W. (2012). Positive couple relationships: The evidence for long-lasting relationship satisfaction and happiness. V S. Roffey (ur.), Positive Relationships: Evidence Based Practice across the World (str. 73-89). New York, NY, ZDA: Springer Science + Business Media.

Murray, S. L., Rose, P., Bellavia, G. M., Holmes, J. G. in Kusche, A. G. (2002). When rejection stings: How selfesteem constrains relationship-enhancement process. Journal of Personality and Social Psychology, 83, 556-573.

Norton, R. (1983). Measuring marital quality: A critical look at the dependent variable. Journal of Marriage and the Family, 45, 141-151.

Orth, U., Trzesniewski, K. H. in Robins, R. W. (2010). Self-esteem development from young adulthood to old age: A cohort-sequential longitudinal study. Journal of Personality and Social Psychology, 98, 645-658.

Pasch, L. A. in Bradbury, T. N. (1998). Social support, conflict, and the development of marital dysfunction. Journal of Consulting and Clinical Psychology, 66, 219-230.

Pasch, L. A., Bradbury, T. N. in Davila, J. (1997). Gender, negative affectivity, and observed social support in marital interaction. Personal Relationships, 4, 36-378.

Pierce, G. R., Sarason, I. G. in Sarason, B. R. (1991). General and relationship-based perceptions of social support: Are two constructs better than one? Journal of Personality and Social Psychology, 61, 1028-1039.

Reis, H. T. in Collins, N. (2000). Measuring relationship properties and interactions relevant to social support. V S. Cohen, L. G. Underwood in B. H. Gottlieb (ur.), Social support measurement and intervention: $A$ guide for health and social scientists (str. 136-192). New York, NY, ZDA: Oxford University Press.

Robins, R. W., Hendin, H. M. in Trzesniewski, K. H. (2001). Measuring global self-esteem: Construct validation of a single-item measure and the Rosenberg self-esteem scale. Personality and Social Psychology Bulletin, 27, 151-161.
Roehling, P. V. in Bultman, M. (2002). Does absence make the heart grow fonder: Work-related travel and marital satisfaction. Sex Roles: A Journal of Research, 46, 273-287.

Rosenberg, M. (1965). Society and the adolescent selfimage. Princeton, NJ, ZDA: Princeton University Press.

Saavedra, M. C., Rogee, R. D. in Chapman, K. E. (2010). Clarifying links between attachment and relationship quality: Hostile conflict and mindfulness as moderators. Journal of Family Psychology, 24, 380-390.

Sanderson, C. A. in Cantor, N. (2001). The association of intimacy goals and marital satisfaction: A test of four mediational models hypotheses. Personality and Social Psychology Bulletin, 27, 1567-1577.

Sanderson, B. in Kurdek, L. A. (1993). Predicting relationship satisfaction and relationship commitment from interdependence, individual differences, and problem-solving variables: Race and gender as possible moderator variables in a sample of dating heterosexual couples. Family Relations, 42, 263-267.

Sciangula A. in Morry, M. M. (2009). Self-esteem and perceived regard: How I see myself affects my relationship satisfaction. The Journal of Social Psychology, 149, 143-158.

Spanier, G. B. (1976). Measuring dyadic adjustment: New scales for assessing the quality of marriage and similar dyads. Journal of Marriage and Family, 38, $15-28$.

Spanier, G. B. in Lewis, R. A. (1980). Marital quality: A review of the seventies. Journal of Marriage and the Family, 42, 96-110.

Verhofstadt, L. L., Buysse, A., Rosseel, Y. in Peene, O. J. (2006). Confirming the three-factor structure of the quality of relationships inventory within couples. Psychological Assessment, 18, 15-21.

Weiss, R. S. (1973). Loneliness: The experience of emotional and social isolation. Cambridge, MA, ZDA: MIT Press.

White, K. M., Speisman, J. C., Jackson, D., Bartis, S. in Costos, D. (1986). Intimacy maturity and its correlates in young married couples. Journal of Personality and Social Psychology, 50, 152-162.

White, L. in Edwards, J. N. (1990). Emptying the nest and parental well being: An analysis of national panel data. American Sociological Review, 55, 235-242.

Wright, C. I. in Busby, D. M. (1997). Relationship satisfaction: Impact and consequences for women's emotional health and treatment. Contemporary Family Therapy, 19, 443-460.

Žnidaršič, S. (2010). Povezava med samospoštovanjem in zadovoljstvom s partnerskim odnosom pri študentih (neobjavljeno diplomsko delo). Filozofska fakulteta 